\title{
Energy Harvesting Technology by Converting Waste Heat Energy from Automobiles
}

\author{
Md Abdullah Al Rakib, Md. Saniat Rahman Zishan and Md. Abid Hasan
}

\begin{abstract}
In this paper, heat energy is used for generating electrical energy by a conversion process. The energy harvesting from the heat of motorbike has become a new source of portable energy for rechargeable gadgets. In contrary, the conventional nonrenewable energy sources have likewise added to an expansion in contamination on the planet and a disintegration of human wellbeing. From the electrical energy, the mobile phone will be charged. A thermoelectric generator has been connected to the hot portion of the motorbike and while riding the bike, any kind of chargeable device will get charged. From the output of the system, approximately the voltage level of about 4.5 volts and around $3 \mathrm{~W}$ have been got which is sufficient to charge the mobile battery and for this system around $89.7 \%$ efficiency has been found. The prototype of this research work has effectively harvested electrical energy from heat using thermoelectric generator and has managed to provide enough power at different speeds of the motorbike.
\end{abstract}

Index Terms - Thermoelectricity, thermoelectric materials, Seebeck unit, heat energy, electrical energy, voltage step-up module, charging issue.

\section{INTRODUCTION}

In the present day, there are numerous issues concerning a worldwide temperature alteration because a bounty of waste warmth is delivered into nature. A thermoelectric generator (TEG), also named a Seebeck generator, is strong position equipment that converts directly into electrical energy over the thermal transformation through a wonder called the Seebeck effect (a type of thermoelectric impact). Thermoelectric generators work like warm motors are fewer cumbersome and have no moving portions. In this case, TEG is normally more costly and less effective [1].

Thermoelectric generators may be used in power plants to transform hot waste into extra electrical force and to improve eco-friendliness in vehicles such as car thermoelectric generators (ATGs). Radioisotope thermoelectric generators use radioisotopes to create the necessary warmth in contrast to control space tests [2].

According to the results of Amrit P. Sharma and his colleagues, these lead-free relaxor-ferroelectric hetero

Md Abdullah Al Rakib Rakib is a undergraduate student of the Department of EEE, American International University-Bangladesh, Dhaka, Bangladesh. Email: alrakib108@gmail.com

Md. Saniat Rahman Zishan is an Associate Professor and Head of the Department of CoE, AIUB, Dhaka, Bangladesh.Email: saniat@aiub.edu

Md. Abid Hasan Abid is an Assistant Professor of the Department of EEE, AIUB, Dhaka, Bangladesh. Email: abid1084@gmail.com structures might be promising candidates for harvesting electrical energy from waste low-grade thermal energy [6]. HaicaiLv In comparison to other reported flexible TEDs, the proposed system that manufactured S-TED produces a high output power of $749.19 \mathrm{nW}$ under a vertical gradient of $30 \mathrm{~K}$ using just three pairs of $\mathrm{p}-\mathrm{n}$ couple, equal to a high output power of $416.22 \mathrm{nW} \mathrm{cm}-2$. Their design philosophy will encourage the development of high-performance TEDs for flexible and wearable applications [7]. Andres Georg Rösch and his colleagues showed a wireless power harvested technology by powering an automated weather sensor that included a Bluetooth module and a voltage regulation system [8]. DingLuo and his colleagues developed a unique fluidthermal-electric multiphysics numerical model to forecast the performance of a thermoelectric generator system used in car waste heat recovery. The model takes into account the whole shape, temperature-dependent material characteristics, topological connectivity among thermoelectric modules, and impedance matching to replicate actual operating circumstances [9].

Three materials are generally utilized for thermoelectric generators. These materials are (Bi2Te3), (PbTe) and ( $\mathrm{SiGe})$. Which material is utilized relies upon the qualities of the warmth source, cold sink, and the plan of the thermoelectric generator. Numerous thermoelectric generator materials are as of now going through research yet have not been popularized. o make a thermoelectric generator module, numerous p-type and n-type couples are associated electrically in the arrangement and/or corresponding to make the ideal electrical flow and voltage. The couples are put between two equal fired plates. The plates have an auxiliary unbending character, a level mounting surface, and a dielectric layer to stop electric short circuits [7].

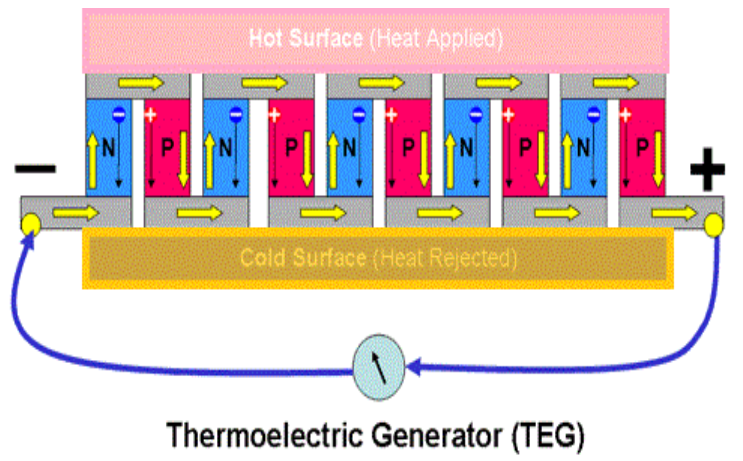

Fig. 1. Schematic diagram of human motion with energy harvester. [8] 


\section{DESIGN OF WASTE HEAT ENERGY HARVESTER}

Fig. 1 shows the central operating theory, including the internal portion of the thermoelectric generator, of the proposed device. The term thermoelectricity alludes to the phenomena wherein a motion of the electric charge is brought about by a temperature gradient or the inverse in which a motion of heat is brought about by an electric expected gradient. These wonders incorporate three impacts; the Seebeck and Peltier impact. The first of the thermoelectric effects were noticed by Thomas Johann Seebeck in 1821. He found that a circuit made out of two unique metals would divert a compass needle if their intersections were kept at two distinct temperatures. At first, he felt that this impact was because of attraction instigated by the temperature distinction, yet it was understood that it was because of a prompted electrical flow. In 1834, the French watchmaker Charles Athanase Peltier saw the second effect [9].

By translating over-temperature contrasts into electric voltage, thermoelectric materials derive power directly from the heat. These components should have both electrical conductivity $(\sigma) \mathrm{t}$ and low thermal conductivity $(\kappa)$ to be acceptable thermoelectric materials. Having no hot conductivity means that when one side gets hot, the opposite side remains cold, which assists with creating a huge voltage while in a temperature slope. The proportion of the extent of electrons stream because of a temperature contrast over that material is given by the Seebeck coefficient (S). The proficiency of an offered material to create a thermoelectric force is administered by its "figure of legitimacy" $Z T=\frac{S^{2} \sigma T}{k}$ (1)

The principle behind it states that

$$
V=\alpha(T h-T c)
$$

Where V-Voltage modification between two unlike metals, $\alpha$ Seebeck coefficient and $T_{h}-T_{c}-$ Temperature variance between hot and cold connections [3].

The electrical field ' $E$ ' is affected by current density and the temperature gradient ' $\Delta \mathrm{T}$ '. The coefficients are recognized by Ohm's law and the Seebeck impact. The electric field is then communicated as,

$$
E=j p+\alpha \Delta \mathrm{T}
$$

The warmth flux ' $q$ ' is additionally influenced by both the field ' $\mathrm{E}$ ' and the temperature gradient ' $\Delta \mathrm{T}$ '. The Thomson relationship and Onsager's guideline yielded the warmth stream density vector (heat flux), which is communicated as [4],

$$
q=\alpha T j-k \Delta \mathrm{T}
$$

Thermocouples produce an open-circuit voltage, considered the Seebeck voltage that is corresponding to the temperature distinction between the hot and reference intersections:

$$
E=\alpha(T-T o)+\beta(T-T o)^{2}
$$

Subsequently, a thermocouple estimation framework should either measure the reference intersection temperature or control it to keep up it at a fixed, known temperature formula for calculating the Seebeck coefficient is given below,

$$
S=-\frac{\Delta \mathrm{V}}{\Delta \mathrm{T}}=\frac{\mathrm{V} \text { hot }-\mathrm{V} \text { cold }}{\text { Thot }- \text { Tcold }}
$$

Where, ' $\mathrm{S}$ ' is the Seebeck coefficient, ' $\Delta \mathrm{V}^{\prime}$ 'is the voltage difference, and ' $\Delta \mathrm{T}$ ' is the temperature difference [5].

The only three semiconductors considered to have both low warm conductivity and strong force factors have been bismuth telluride (Bi2Te3), lead telluride, for a long time $(\mathrm{PbTe})$, and silicon-germanium ( $\mathrm{SiGe})$. These materials have extremely uncommon components that make them extravagant compounds. Today, the warm conductivity of semiconductors can be brought down without influencing their high electrical properties utilizing nanotechnology. This can be accomplished by making nanoscale highlights, for example, particles, wires, or interfaces in mass semiconductor materials. Notwithstanding, the assembling cycles of nanomaterials are as yet testing [6].

Fig. 2. Block diagram of the waste heat energy harvesting system.

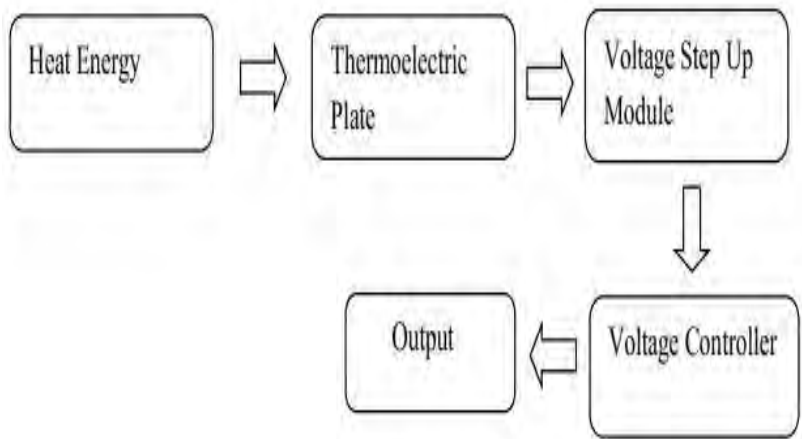

Figure 2 shows the proposed model of the project. The hot part of the motorbike has four TEG plates involved in it. In fig. 3 after using TEGs we used a voltage regulator circuit that make the voltage fixed for charging phone.

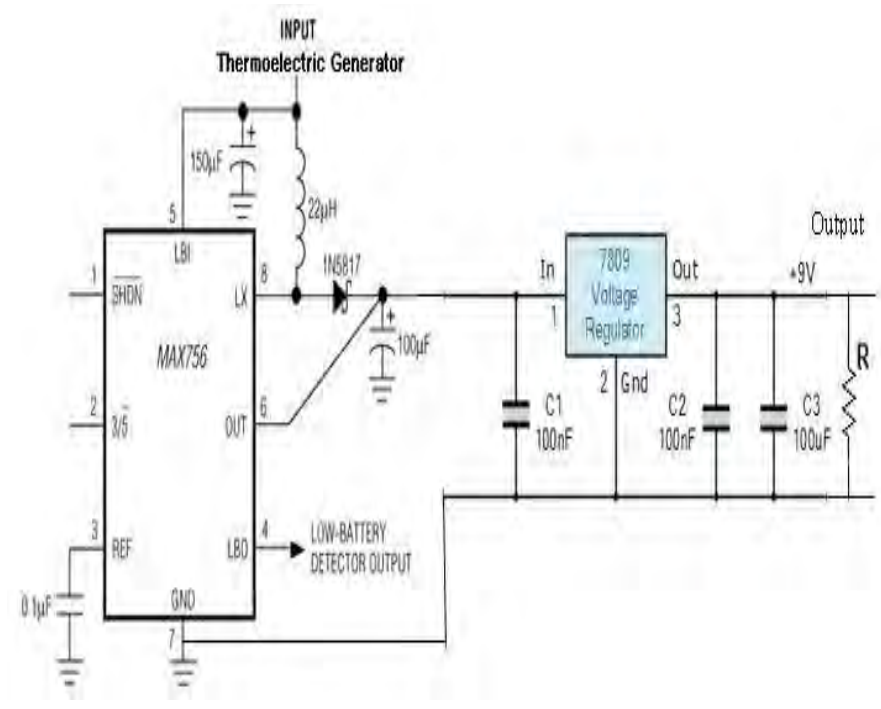


Fig. 3. Circuit diagram of human motion with energy harvester.

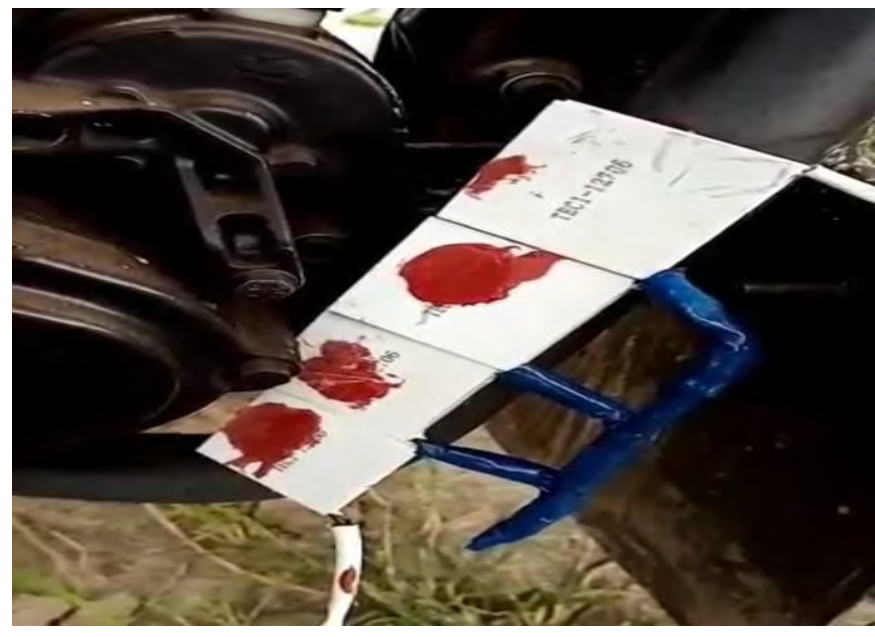

Fig 4. Thermoelectric generator with the motorbike.

\section{SIMULATION RESULTS}

When, the thermoelectric properties is written as seebeck coefficient(s) is $0.0003 \mathrm{~V} / \mathrm{k}$, contact resistance(r) is $1 \mathrm{e}$ $10 \mathrm{~m}^{2} \times \mathrm{ohm}$, Thermal conductivity $(\mathrm{k})$ is $1.2 \mathrm{~W} / \mathrm{mk}$, electrical conductivity(sigma) is $110000 \mathrm{~S} / \mathrm{m}$ and geometry parameters is written as thickness (d) is $0.0003 \mathrm{~m}$ and fraction of coverage (\%) is 50. In the heat transfer conditions, hot working fluid bulk temperature $\left(\mathrm{T}_{\mathrm{hf}}\right)$ is $320 \mathrm{~K}$ and cold working fluid bulk temperature $\left(\mathrm{T}_{\mathrm{cf}}\right)$ is $303 \mathrm{~K}$, hot side heat exchanging area is $1 \mathrm{~m}^{2}$ and hot side effective heat transfer coefficient is $300 \mathrm{w} / \mathrm{m}^{2} \times \mathrm{k}$, the power density will be,

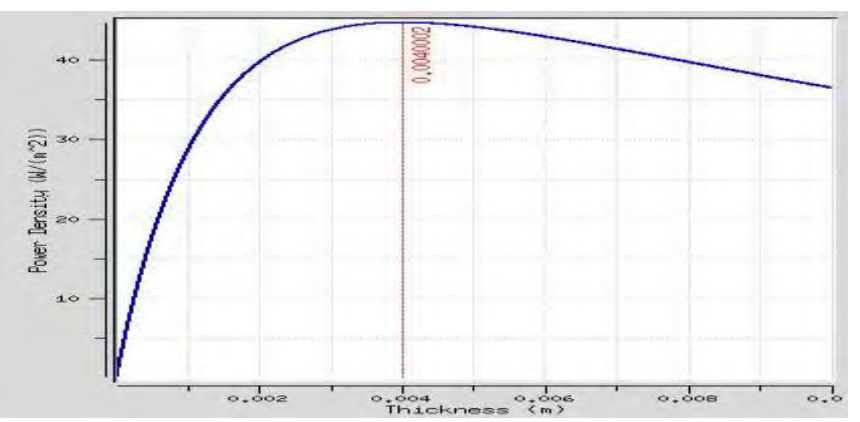

Fig. 5. Power density graph vs thickness

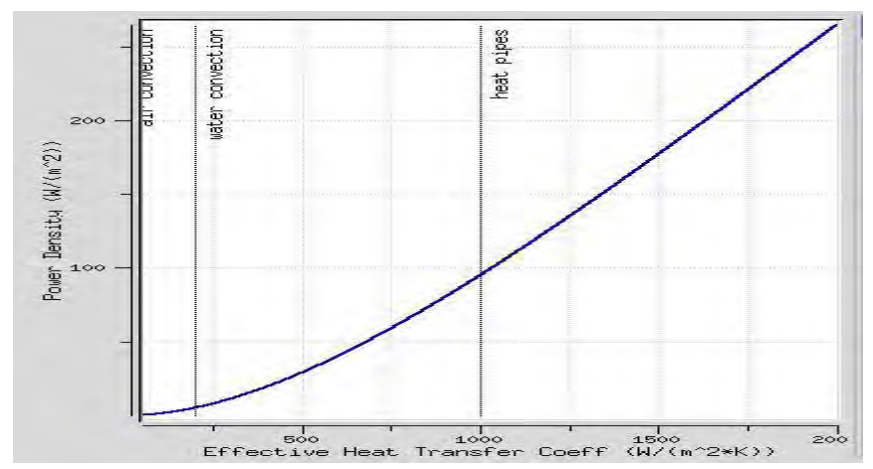

Fig. 6. Power density vs effective heat transfer coefficient graph.

In fig. 6. It can be noted that as the effective heat transfer coefficient is increasing the power density curve is also increasing.

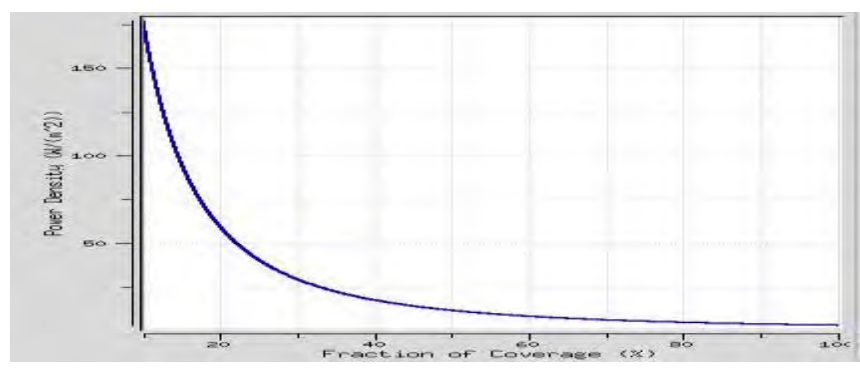

Fig. 7. Power density vs a fraction of coverage graph.

In this fig. 7. It can be noted that when the fraction of coverage is increasing the power density is decreasing as well. Here the output parameters are power density and power output are $11.6044 \mathrm{w} / \mathrm{m}^{2}$ and $5.802 \mathrm{w}$ respectively.

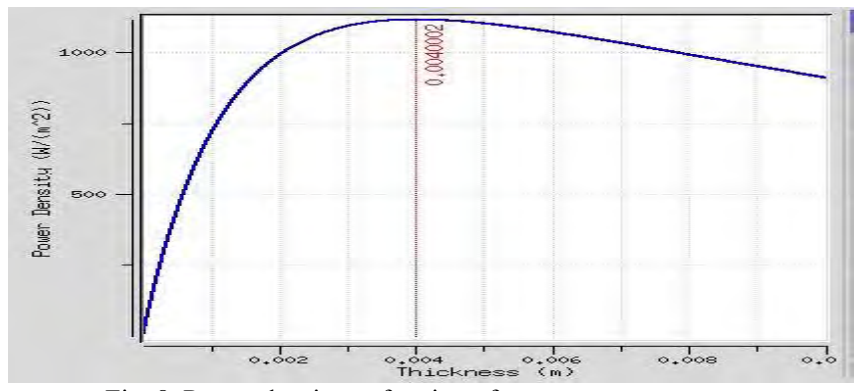

Fig. 8. Power density vs fraction of coverage.

If the other parameters remain the same and just in the heat transfer conditions, hot working fluid bulk temperature (Thf) is $388 \mathrm{~K}$ and cold working fluid bulk temperature (Tcf) is $303 \mathrm{~K}$, hot side heat exchanging area is $1 \mathrm{~m}^{2}$ and hot side effective heat transfer coefficient is $300 \mathrm{w} / \mathrm{m} 2 \times \mathrm{k}$, the power density will be,

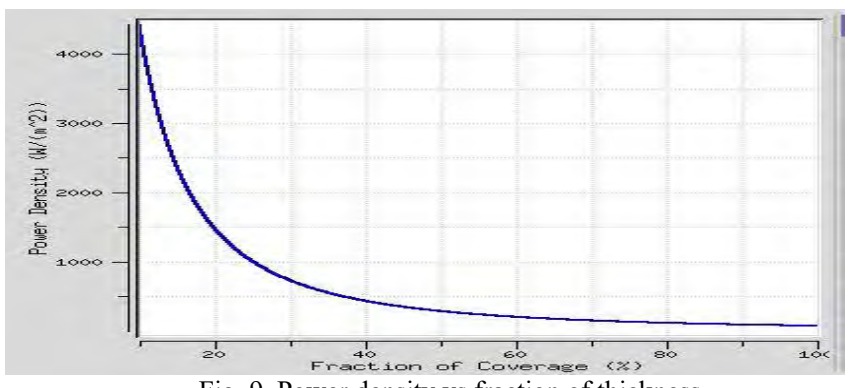

Fig. 9. Power density vs fraction of thickness.

In fig. 9. states that as the function of thickness has been increased, the power density has been increased also.

In fig. 8. and fig. 10, the fraction of coverage and the power density vs the heat transfer coefficient respectively is increased when the temperature difference was increased. Here the output parameters are power density and power output are $290.12 \mathrm{w} / \mathrm{m}^{2}$ and $145.06 \mathrm{w}$ respectively 


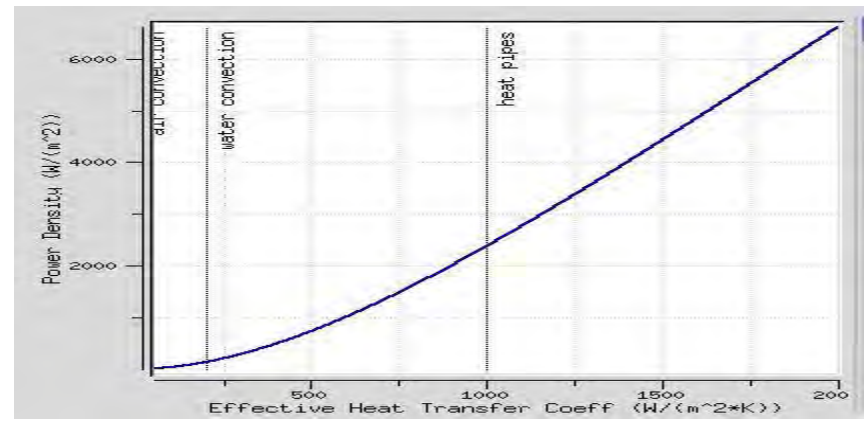

Fig. 10. Power density vs effective heat transfer coefficient graph.

\section{EXPERIMENTAL RESULTS}

Power calculation has been done for four different speeds. When the starts running the values of the voltage and current have been got. The harvester was tested during the motorbike engine starts running and from that voltages are produced. From that voltage, a mobile phone can be charged during riding a bike. In the project, a converter is used (step-up converter) that steps up the voltage (whereas changing the phone) from its information. Sometimes it is called a boostup converter.

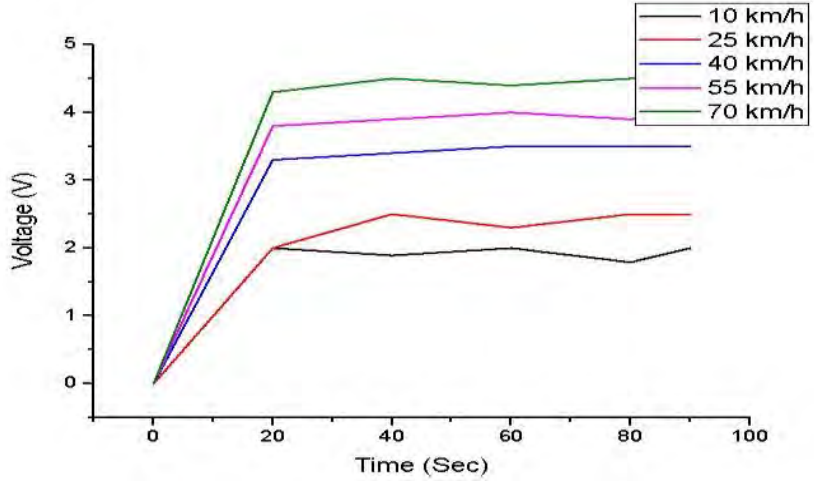

Fig 11. Voltage vs time at the speed of $10 \mathrm{~km} / \mathrm{h}$.

Figure 11shows the different voltage values vs time at different speeds. The experimental value of the speed of the motorbike was taken from $10 \mathrm{~km} / \mathrm{h}$ to $70 \mathrm{~km} / \mathrm{h}$. As the speed was increased, the voltage had also increased. At speed of $10 \mathrm{~km} / \mathrm{h}, 25 \mathrm{~km} / \mathrm{h}, 40 \mathrm{~km} / \mathrm{h}, 55 \mathrm{~km} / \mathrm{h}$ and $70 \mathrm{~km} / \mathrm{h}$, the voltage

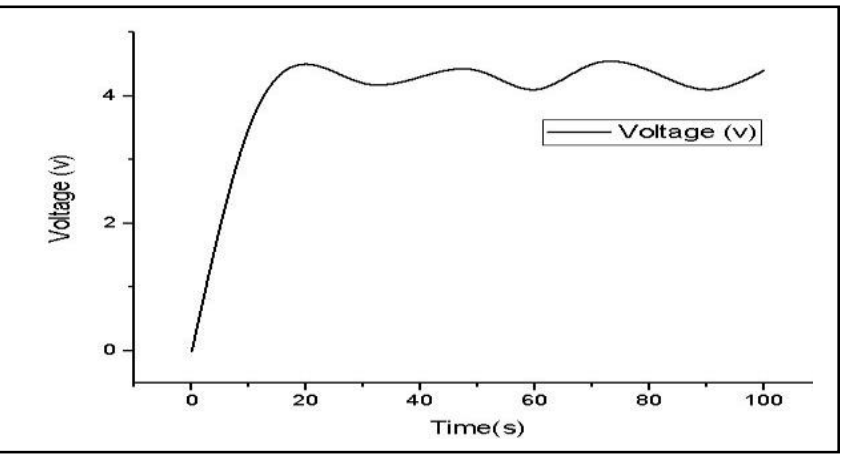

Fig. 12. Voltage vs time graph

had raised to $2 \mathrm{v}, 2.8 \mathrm{v}, 3.3 \mathrm{v}, 4 \mathrm{v}$ and $4.5 \mathrm{v}$ in the multi-meter reading respectively.

Just in Fig. 12 and 13, when the temperature is elevated at a time, voltage and current rise. As increasing the speed of the motorbike, the temperature of the engine was also increased.

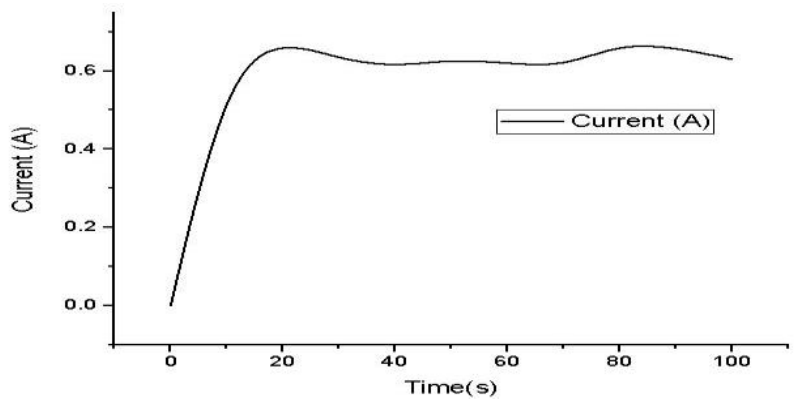

Fig. 13. Current as a function of time.

When the speed of the motorbike is increased slowly voltage converter (MAX757) will increase the voltage and when the speed of the motorbike is increased fast, the voltage controller (LM7805) will control the voltage. Here voltage regulator is used to regulating or fixing the voltage at $4.5 \mathrm{v}$. It can be seen in Fig. 12 and Fig. 13 that the fixed amount of voltage and current have been got. By this voltage mobile or any kind of device can be charged.

The output voltage will be the same after using the boost converter MAX757 and the voltage controller as well. By the voltage, the mobile phone has been charging. Cell phones use Li-Ion batteries. They are ostensibly $3.7 \mathrm{v}$ which is half charge and transported at the voltage. At $100 \%$ charge, they are $4.2 \mathrm{~V}$. So a $4.5 \mathrm{~V}$ charger is needed.

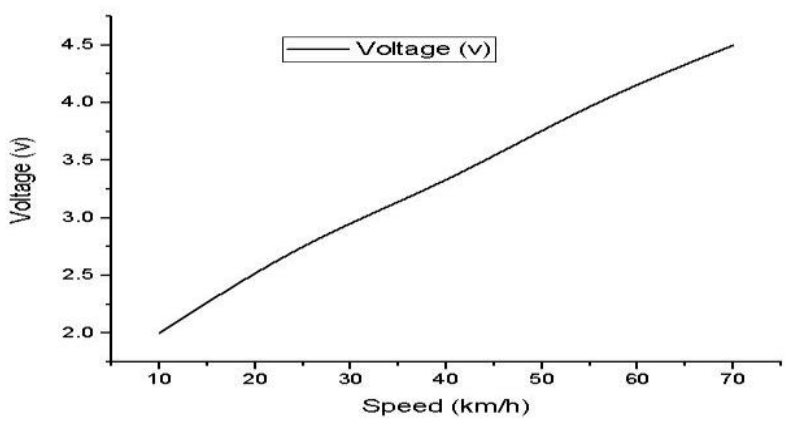

Fig. 14. Voltage vs speed graph.

In fig. 14. output voltage curve has been got with different speeds like above. Here voltage values have been taken at a different speed of the motorbike. A voltage converter is used after receiving the voltage values, comprising two semiconductors in either case (a diode with a transistor) and one energy stockpiling part at any rate: a resistor, inductor, or both in a combination. The step-up circuit is essential utilizing 
only one diode, an inductor, and a capacitor. Fig. 14. represents voltage vs speed curves where voltage is increasing with speed.

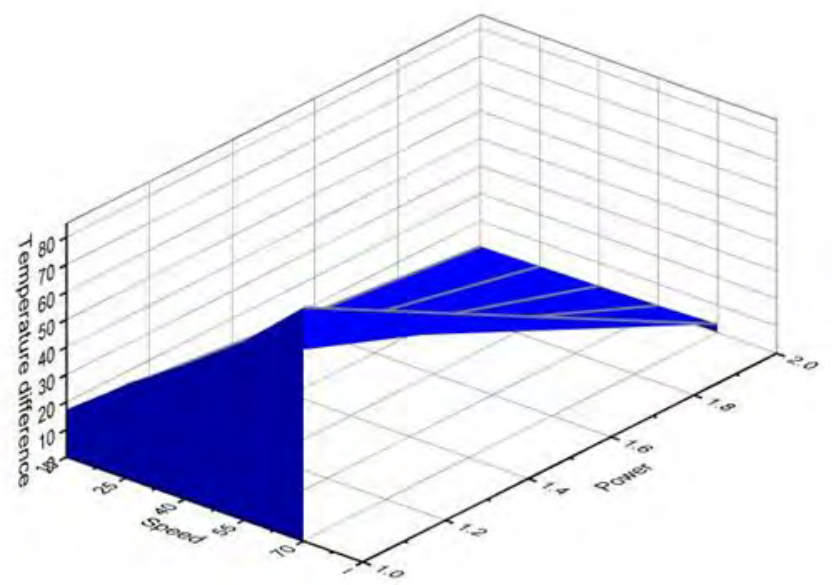

Fig. 15. Output power, temperature, and power vs speed graph.

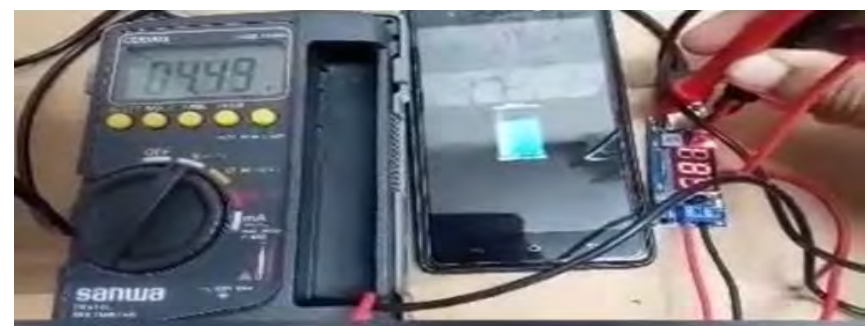

Fig. 16. The output voltage of the prototype.

TABLE I. OUTPUT VOLTAGE AND CURRENT AT DIFFERENT TEMPERATURE

\begin{tabular}{|l|l|l|l|}
\hline No. & $\begin{array}{l}\text { Temperature } \\
\text { difference } \\
\left({ }^{0} \mathrm{C}\right)(\mathrm{Th}-\mathrm{Tc})\end{array}$ & Voltage & Current \\
\hline 1 & 17 & 2.0 & 0.37 \\
\hline 2 & 34 & 2.8 & 0.42 \\
\hline 3 & 49 & 3.3 & 0.5 \\
\hline 4 & 65 & 4.0 & 0.54 \\
\hline 5 & 85 & 4.5 & 0.68 \\
\hline
\end{tabular}

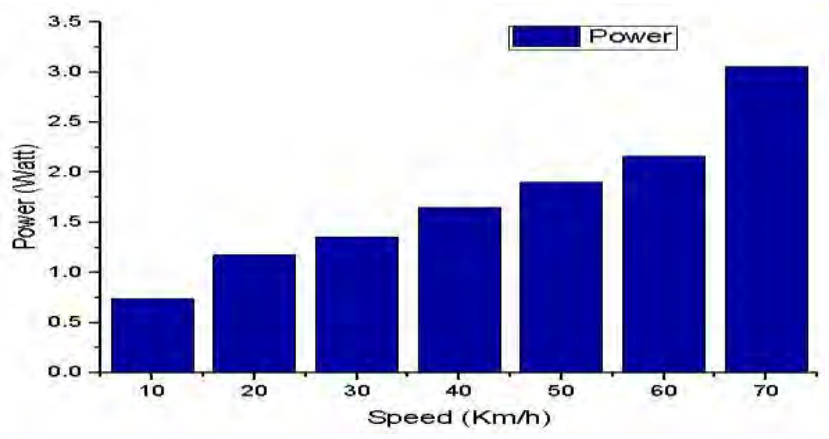

Fig. 17. Output power without converting the voltage at different speeds.
From microwatt to a kilowatt and past generators, thermoelectric generators are fully flexible. The measure of intensity created relies upon the qualities of the warmth source, the cold sink, and the plan of the thermoelectric generator.

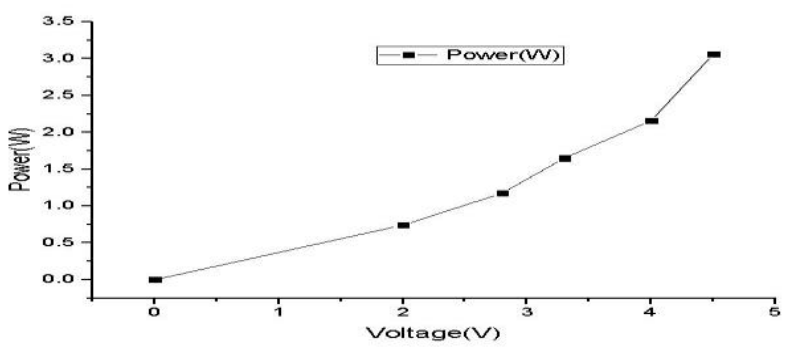

Fig. 18. Power vs voltage graph.

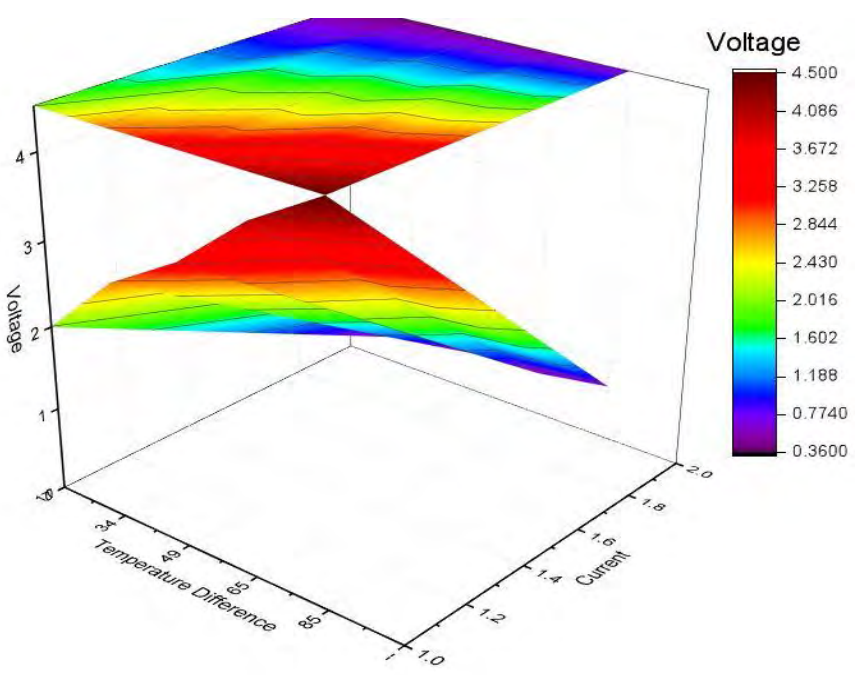

Fig. 19. Output voltage and current vs temperature difference.

Thermoelectric generators are solid-state gadgets. Having no moving parts to break or destroy makes them truly dependable. Thermoelectric generators can keep going for quite a while. The Voyager 1 thermoelectric rocket generator has been active for a very long period because of this composition. It has gone more than 13 billion miles with no upkeep or fixes. Thermoelectric generators can be intended to be quiet. Thermoelectric generators don't need any ozonedepleting substances to work. Some energy transformation advances do. Thermoelectric generators don't have limitations on energizes that can be utilized to create the required warmth. Numerous other energy change advances do [10].

\section{CONCLUSION}

While TEG innovation has been utilized in military and aviation applications for quite a long time, new TE materials 
and frameworks are being created to produce power utilizing low or high temperatures squander heat, and that could give a critical open door sooner rather than later. This part has tended to the structures and utilization of TEGs in different settings. It has risen that the TEG is a reasonable answer for energy gathering, ready to gracefully electrical loads in moderately low-power applications. TEG productivity is additionally ordinarily low. In this way, the upsides of utilizing TEG must be found in the qualities of explicit applications in which there is an essentially high-temperature contrast over the TEG framework, and different arrangements with higher proficiency can't be applied due to different impediments. In here, as a load we are using a phone, that's why we got the values of current. In these cases, TEGs might be completely serious with different arrangement.

Average efficiency of this TEG has been got around $89.705 \%$.Specifically, the utilization of TEGs is completely steady with the arrangement of efficient power energy through energy gathering from even little temperature contrasts. By and by, there is a developing enthusiasm for the capability of thermoelectric applications. For the future, quicker improvement of TEG arrangements can be normal in a more extensive scope of efficient green energy applications [11].

\section{REFERENCES}

[1] vlab.amrita.edu, "Thermo Couple-Seebeck Effect," 2011. [Online]. Available:

https://vlab.amrita.edu/?sub=1\&brch=194\&sim=351\&cnt=1.

[2] A. N. Abd Razak, N. M. Nor and T. Ibrahim, "Heat energy harvesting for portable power supply," in 2011 5th International Power Engineering and Optimization Conference, 2011.

[3] A. Sakai, S. Minami, T. Koretsune, T. Chen, T. Higo, Y. Wang, T. Nomoto, M. Hirayama, S. Miwa, D. Nishio-Hamane and others, "Iron-based binary ferromagnets for transverse thermoelectric conversion," Nature, vol. 581, p. 53-57, 2020.

[4] D. Enescu, "Thermoelectric energy harvesting: basic principles and applications," Green energy advances, p. 1, 2019.

[5] M. D. Rowe, G. Min, S. G. K. Williams, A. Aoune, K. Matsuura, V. L. Kuznetsov and L. W. Fu, "Thermoelectric recovery of waste heat-case studies," in IECEC-97 Proceedings of the Thirty-Second Intersociety Energy Conversion Engineering Conference (Cat. No. 97CH6203), 1997.

[6] Sharma, Amrit P., et al. "Lead-free relaxor-ferroelectric thin films for energy harvesting from low-grade waste-heat." Scientific Reports 11.1 (2021): 1-10.

[7] Lv, Haicai, et al. "A flexible spring-shaped architecture with optimized thermal design for wearable thermoelectric energy harvesting." Nano Energy 88 (2021): 106260.

[8] Rösch, Andres Georg, et al. "Fully printed origami thermoelectric generators for energy-harvesting." npj Flexible Electronics 5.1 (2021): 1-8.

[9] Luo, Ding, Zeyu Sun, and Ruochen Wang. "Performance investigation of a thermoelectric generator system applied in automobile exhaust waste heat recovery." Energy 238 (2022): 121816.

[10] A. Piggott, "How Thermoelectric Generators Work," 2016.

[11] T.-H. Liu, J. Zhou, M. Li, Z. Ding, Q. Song, B. Liao, L. Fu and G. Chen, "Electron mean-free-path filtering in Dirac material for improved thermoelectric performance," Proceedings of the National Academy of Sciences, vol. 115, p. 879-884, 2018.

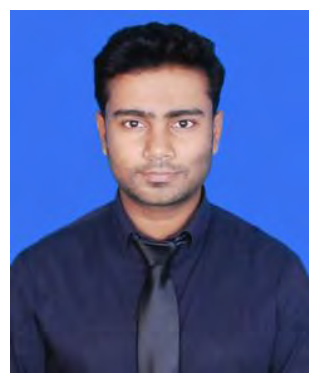

Md Abdullah Al Rakib received Bachelor of Science (B.Sc.) in EEE from American International University-Bangladesh (AIUB). He started his career in September 2018 at City University-Bangladesh (CUB) as Lecturer in the Dept. of EEE. His research interest is focused on Power electronics, IoT, and Telecommunication.

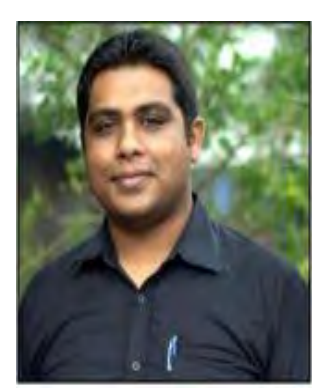

Md. Saniat Rahman Zishan received B.Sc. in Electrical and Electronic Engineering and Master of Engineering in Telecommunications degree from American International University Bangladesh (AIUB) On September 2009, he started his teaching career as a lecturer in AIUB. At present he is serving as an Associate Professor at the Department of Electrical and Electronic Engineering (EEE) \& Computer Engineering (CoE) of AIUB. He is also serving as the Head of CoE Department. He is enrolled for PhD Degree at University Sultan Zainal Abidin, Malaysia. Mr. Zishan is member of the Institute of Electrical and Electronics Engineers (IEEE) and Institution of Engineers, Bangladesh (IEB). His current research interest includes Wireless Communication, Signal Processing, E-Health System, Telemedicine, Robotics and AI.

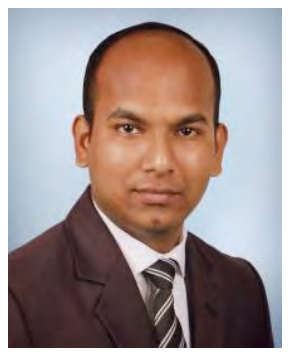

Md. Abid Hasan received the M.Sc. degree in Mechatronic from the University of Siegen, Germany in 2016, and B.Sc. degree from the American International University Bangladesh (AIUB) in 2013. Since August 2017 to January 2019 he had been a lecturer of EEE department in City University Bangladesh. Currently he holds lecturer position of EEE \& CoE department of AIUB. His research focuses on Real time Embaded system design, Indoor Localization, Sensor Fusion, Wireless Sensor Networks, Filtering Technique and Signal Processing. 